men who return permanently to work underground does not exceed twenty-five per cent. Many men reach a state of "equilibrium" and continue to work for years after the onset of the disease. Remedy lies in prevention, and it has been suggested that the illumination of the candle pit, where nystagmus is rare, should be taken as a standard for the safety lamp pit.

The question of improvements in the miners' safety lamp is arousing great interest at the present time, and a Home Office Committee is dealing with the subject.

\title{
ABSTRACTS
}

\section{I-ORBITAL ANAPLEROSIS}

Lagrange (Bordeaux).-Orbital anaplerosis. orbitaire.) Arch. d'Ophtal., March-April, 1919.

(De l'anaplérose

Under the term anaplerosis (derived from the Greek $\dot{a} \nu a \pi \lambda \eta o^{\prime} \omega$, to fill up), Lagrange describes $\mathrm{a}^{\cdot}$ new procedure designed, like many other operations introduced during the last forty years, to provide a substitute for the enucleated eyeball, and to form a satisfactory stump on which an artificial eye may rest, and from which the latter may derive movement. The author reviews briefly the methods which have hitherto been employed; the pseudo-plastic devices, such as Mules's operation, the heteroplastic grafts, e.g., rabbit's eyes, and more recently homoplastic grafts of skin and fat, and of cartilage. None of these methods has proved really satisfactory; the best aesthetic results have been obtained in cases in which abscission of the anterior parts of the eyeball has been performed and this procedure, the writer recognizes, is suitable for a very limited number. The operation now described by Lagrange seems to the reviewer to be based on sound principles and to give greater promise of success in filling up the cavity of the orbit than any others with which he is acquainted. Unfortunately, the procedure is one which no written description, unaided by diagrams, will portray adequately and intelligibly. Those who are interested should study the original article.

The operation is suitable for cases of immediate enucleation, or for those in which the eyeball has been removed previously. The technique, though lengthy, is simple, and is given in detail by the writer and illustrated by numerous helpful diagrams. It consists essentially in obtaining a pedicled flap of connective tissue and fat from the region adjoining the external angle of the orbit. This flap is exposed by a $\mathrm{T}$-shaped incision through the skin. In the space 
thus formed an oval-shaped flap, about $7 \mathrm{~cm}$. long, $6 \mathrm{~cm}$. broad, and $2 \mathrm{~mm}$. thick, is dissected up from the distal end. The pedicle is attached to the skin and soft parts at the internal angle of the orbit. This flap is introduced into the capsule of Tenon under the tissues at the orbital angle, and entirely subconjunctivally. When the flap has been drawn into Tenon's capsule, it has to be attached to the cut ends of the recti muscles; the technique of this stage of the operation should be studied by the aid of the diagram; the plan of attaching the muscles to the flap has been devised with the view of placing the flap as high in the orbit as possible, in order that the hollow behind the upper lid (so noticeable a deformity in most cases after enucleation) may be rendered less conspicuous.

In cases in which the eyeball has been removed at a former date, the latter part of the operation is varied, it being impossible to attach the flap to the recti tendons. In such cases the tip is sutured to the upper lid close to the inner canthus. The conjunctiva in this group of cases should not be incised anteriorly, the preparation of a bed for the flap and its introduction from, the temporal angle being completed subconjunctivally. It seems scarcely necessary to add, in the words of the author, that such an operation is suitable only for cases in which the orbit is free from infection of any kind.

J. B. LAWFORD.

\section{II-ICTERO-HAEMORRHAGIC SPIROCHAETOSIS}

(I) Weekers, L. - Recurrent iritis in spirochaetosis, icterohaemorrhagica. (Iritis récidivante dans la spirochétose ictéro-hémorrhagique.) Arch. d'Ophtal. Nov.-Dec., I9I8.

(1) In the Sept.-Oct. number of the Archives d'Ophtalmologie, Weekers and Firket recorded a series of observations on the ocular complications of spirochaetosis. Weekers now publishes a supplementary paper containing notes of one case in which the iritis occurring during the acute stage of the disease, recurred on three occasions during the nine months after convale'scence was established. The recurrences were severe but cleared up without any permanent damage to sight. Other causes for iritis, such as syphilis, were excluded.

J. B. LAWFORD.

(2) Moret (Chef du service d'ophtalmologie à l'Hopital Militaire belge de Bourbourg). - Ocular troubles in ictero-haemorrhagic spirochaetosis. (Troubles oculaires dans la spirochétose ictéro-hémorragique.) La Clin. Ophtal., January, 1919. (From Archiv Med.belges, December, 1919) 
(2) This article by Moret is of much interest and well written. The author's own "Conclusions," slightly amplified, will form an excellent abstract :

1. Serious cases of ictero-haemorrhagic spirochaetosis are accompanied by various troubles of the visual apparatus. (In the slight forms the author has not found anything of ophthalmological interest).

2. The affection is to be divided into two periods, namely, the acute or congestive, and the period of decline - the anaemic period. Different troubles having different causes correspond to these two periods.

3. During the congestive period:

(a) Vaso-motor affections of the external and sometimes of the internal eye membranes.

Conjunctival congestion is an early symptom, and is sometimes accompanied by a corresponding congestion of the uveal tract and hyperaemia of the deep membranes. (Extreme redness of the discs as if there were a commencing papillitis.)

This vaso-dilatation is not inflammatory in origin. It appears to to be due to a marked interference with the angiotonic function of the suprarenals. (As an example of the non-inflammatory nature of this congestion may be mentioned the fact that the great conjunctival congestion is entirely unaccompanied by discharge.)

(b) Haemorrhages of the external and sometimes of the deep membranes of the eye. These haemorrhages are small, and in the author's opinion are due, not to rupture of blood-vessels, but to the fluid state of the blood and the dilated condition of the capillary vessels - in fact, diapedesis.)

(c) The ictero-haemorrhagic spirochaete may locate itself in the iris and give rise to iritis. (Thus this organism can bring about an inflammation of the iris through the blood in the same manner as the spirochaeta pallida. But in most cases there is not iritis but merely congestion of the iris of vaso-motor origin. This is shown by the behaviour of the iris to vaso-constrictor mydriatics like adrenalin and cocain, on the one hand, and to atropin and homatropin, on the other. The pupil does not dilate to the former but dilates to the latter.

4. During the period of anaemia there are subjective symptoms such as are commonly observed in profound anaemias; such are asthenopia and muscae volitantes. Ophthalmoscopically there is a certain degree of retinal anaemia. In some cases, however, there is an appearance of neuro-retinitis out of all comparison with symptoms. (The visual acuity is normal, there are no scotomata and no dyschromatopsia.) A similar state of affairs is known to occur in other essential or symptomatic anaemias.

ERNEST THOMSON. 


\section{III.-OCULAR SPARGANOSIS}

Motais, François. - Ocular. sparganosis. (La sparganose oculaire.) Arch. d'Ophtal, September-October, 1918.

The title "Ocular Sparganosis" is used by Motais to designate the invasion of the cellular tissue of the orbit of the eyelids by the sparganum Mansoni, the larval form of one of the cestoda.

Sparganum was discovered by Manson, in 1882, in the pleura and peritoneum of a Chinese. Since that date the larva has been identified by Scheube, Ijima, Murata in Japan, by Sambon in East Africa, by Daniels in British Guiana, by Casaux in Tonquin, and by Garde and Rongier in Annam.

Motais now publishes a case under his observation, in which the larva was removed from the eyelid of a child. The parasite has been found once in serous membranes, four times in the genitourinary system, twice in the limbs, and seven times in the annexes of the eye.

The adult form, hitherto unidentified, is classed among the Dibothriocephalidae.

The larva is a small flat riband-like worm, a few centimetres in length. It has an enlarged oval head (see sketch in Motais' paper) $3 \mathrm{~mm}$. long by $2.5 \mathrm{~mm}$. wide; the top shows a median transverse invagination bordered by two ridges. The body is $1.7 \mathrm{~mm}$. in width, and its extremity is rather ragged. The head and the. anterior part of the body are transversely but irregularly striated.

Henry and Bauche have on several occasions found the sparganum in the connective tissue of pigs in Annam. Motais has been able to examine one of their specimens, and believes it to be exactly similar to the larva removed from his patient. De Ratz, of BudaPesth, has found similar larvae in the flesh of pigs in Hungary.

Motais' patient was a boy, aged 11 , who was born and had always lived in Hué (Annam). For about a year the parents had noticed occasional redness of the eyes and oedema of the eyelids. A small swelling on the left upper lid had appeared at the beginning of the trouble, and had slowly increased in size. When' seen, there was a deep mobile elastic tumour, the size of a haricot bean, at the upper outer end of the upper lid. This was easily removed through the skin; it was situated in the connective tissue and in contact with the palpebral conjunctiva. The larva was found in a small fluid-containing cavity in the mass. The tumour was composed of fairly dense vascular connective tissue, surrounded by fat.

J. B. LAWFORD. 


\section{IV.-GLAUCOMA AND GLAUCOMA OPERATIONS}

\section{-}

(.I) Stirling, J. W. (Montreal).-Some notes on the blockage of the trephine opening after the Elliot operation. Arch. of Ophthal., Vol. XLVI, No. 4, p. 352, 1917.

(i) Stirling opens his paper by saying: "The blockage of the trephine opening as a sequel to the Elliot operation for glaucoma is not of common occurrence. In forty-six operations of my own it developed in three." In addition he has the notes of the anatomical examination of an eye operated on by another surgeon. In three out of the four cases, the glaucoma was of long standing, and was congestive in type. In all three early blockage occurred. In the fourth, the filling up of the hole was delayed nearly a year, and in this one the hyperplasia of the conjunctival and episcleral tissue was apparently the main cause of the blocking. Stirling thinks the stitch may have been responsible. In the remaining cases the hyperplastic tissue was apparently of uveal origin. Stirling says : "the cause of the blocking has hence to be sought in the origin of the inflammation of the iris, associated with that of the subconjunctival tissue." $\mathrm{He}$ leans to the view that the condition is an auto-toxaemic one, lighted up by the operative traumatism, and is not due to a germ infection. Anyone who has met cases of this kind will readily recognize the type of eye that Stirling describes. One knows well, before one operates, that there is a danger of the filling up of the trephine hole at an early date, and the question rises in one's mind, how far these are truly congestive cases, and whether a septic element is not present in them. Stirling prefers to talk of them as auto-toxaemic. It matters little how we label them, so long as we can recognize them, but the reviewer believes that time will decide in favour of their origin being septic in nature, the septic element being present before operation, and not being introduced by it. In the latter respect he cordially agrees with Stirling. In such cases it matters little what operation is employed, the resulting failure will be the same in all alike.

R. H. Elliot.

(2) Ewing, A. E. (Șt. Louis).-Post-ciliary scleral trephining for glaucoma, Amer. Jl. of. Ophthal., July, 1917.

(2) Ewing relates at considerable length two cases of glaucoma, one with almost no vision and tension Schiötz 50, the other with vision 20/15 and tension Schiötz 45. In each of these cases Ewing performed Argyll Robertson's operation of trephining behind the region of the ciliary body. The site chosen was between the superior and external recti, $7 \mathrm{~mm}$. and $9 \mathrm{~mm}$. behind the corneal margin respectively in the two cases. Conjunctival flaps of $8 \mathrm{~mm}$. 
raised from below were employed. Ewing has been satisfied with the results obtained, but it will be generally admitted that no great hopes can justıfiably be based on only two operations. One feels that the writer may, after a more extended trial, be less satisfied than he is at present. This is what he says about the results in these two cases. "From the standpoint of the ideal the operations are not wholly successful, because the tension in neither of the eyes is normal. From the practical standpoint the condition in the advanced glaucomatous eye is entirely satisfactory, the globe having become quiet and the pain having been relieved. The tension in the second case is reduced about one-third. This is a material gain." For the author's arguments and views in general the reader is referred to the original.

ERNEST THOMSON.

(3) Clapp, C. A. (Baltimore).-Corneo-scleral trephining. Amer. Jl. of Ophthal., Series 3, Vol. I, No. 2, February, I9I8.

(3) It is not often in these days that one comes across a wholesale denunciation of the trephine operation. Clapp as the result of five cases operated on unsuccessfully, one of them by Colonel Elliot himself, comes to these conclusions: (1) The corneo-scleral trephine operation for glaucoma has late resultswhich may develop even years after the operation. (2) Rarely if ever should it be the operation of choice. (3) It should be tried where iridectomy has failed. (4) Some reports in cases of buphthalmos would seem to warrant further trial in this condition. The results of the five cases may be summarized as follows: (1) Neither permanent lowering of tension nor restoration of vision. (2) Late infection after one year. (3) Simple chronic glaucoma became fulminating on third day after operation. (4) Col. Elliot's case. Operation on both eyes. Vision of one eye before operation was 20/20, after operation it was 20/100 and remained so four years later. (5) Iritis five months after operation, subsequent blindness.

\section{ERNEST THOMSON.}

(4) Morax, V. (Paris.)-Clinical notes on some early atypical signs of subacute glaucoma. Ann. d'Oculist, Vol. CLV, February, I9I8.

(4) In this short paper Morax points out that we are much beyond the stage when glaucoma is diagnosed from the nasal field retraction and the disc cupping, both of which can come only after, say, six to twelve months of hypertension, but he does not wish to enlarge on the well-known classical signs but draws attention to orbito-facial pain like a deep bone pain, giving rise to suspicions of a sinus or periosteal affection, and to watering. The cases he discusses are those where one or both of these phenomena were alone present, coupled solely with tonometric changes and relieved 
by pilocarpin. He advocates the constant use of the tonometer in cases where ocular, cephalic, or facial pains are not clearly explicable, and this would, he affirms, do away with many mistakes. Two cases with two-year old and six-months old orbito-facial pains had gone to the oto-rhinologist for relief whereas there was no sinus affection but a need for eserin. In this connection it is noteworthy that in the days of Demours glaucoma was regarded as an inflammation of the orbital periosteum and of the frontal sinus mucous membrane. Short notes are given of four cases, viz. man of 43 and one of 50, and woman of 46 and one of 35 , in whom only these phenomena were noticed and in whom eserin or pilocarpin gave complete relief.

W. C. Souter.

(5) Lamb, Robert Scott (Washington, D.C.)-A theory as to the origin of glaucoma. Amer. Jl. of Ophthal., Series 3, Vol. I, No. 3, March, 1918.

(5) This article is mainly of a speculative character. The author suggests that acute inflammatory glaucoma is probably the result of a sudden imperative demand upon the adrenals under conditions in which the demand cannot be fully met, with the result that there is a "precipitate lowering of sympathetic tone" which throws the balance under the control of the vagus, " in the presence of predisposing factors, such as high hyperopic eyeballs and other anatomic abnormalities." The result of vagus control is the "venous congestion and marked turgescence which is so commonly seen in the later stages of an acute inflammatory glaucoma." The obvious indications are the use of pilocarpin and adrenalin, the former " acting through the vagus, will give us sufficient relaxation to permit the re-establishment of the circulation, more normal tone and a gradual restoration of the local structures to size and condition approaching that which immediately preceded the acute attack." The author states that this method of treatment has been tried out in thirteen cases and has been successful in each case in restoring the eye to a relatively normal condition, so that the dangers from a subsequent operation to increase the drainage, were undoubtedly very much lessened.

ERNEST THOMSON.

(6) Colombo, Gianluigi (The Ophthalmic Clinic of the University of Parma).-On the importance of irido-ciliary entanglement in sclero-corneal trephining (Elliot) for glaucoma. (Sull importanza dell'impegno irido-ciliare nella trapanazione sclero-corneale (Elliot) contra il glaucoma.) Arch. di Ottal, March-August, I9I 8.

(6) Colombo divides his interesting and suggestive paper into two parts. The first deals with his experimental work in which he trephined a number of rabbits' eyes, and after excision at various 
later dates examined them microscopically. The trephine employed was $1.5 \mathrm{~mm}$. in diameter, and in all a peripheral iridectomy, leaving the sphincter untouched, was performed. The trephine hole was made well forward to avoid injury to the ciliary body. The intraocular pressure was always considerably lower after the operation, and remained so up to four months (the latest period at which the eyes were removed). A careful description of the microscopical anatomy of the eyes is given, and illustrated by three excellent plates. The most important point found in practically all the specimens, was that the ciliary body had been dragged forward, and was implicated in the scar. Clinically there was no evidence of this to be seen after careful examination. Colombo rightly points out that experiments on an eye such as that of the rabbit are not necessarily conclusive evidence that the same results happen in the human eye.

In the second part he discusses the clinical work of other authors, as well as the bearing of his experimental work on the results obtained. He notes that Meller, Sattler, Di Marzio, and Guglianetti had expressed surprise at finding an irido-ciliary entanglement in human eyes, in which they had no clinical evidence of its existénce. He points out that in Elliot's operation the conditions favour the involvement of uveal tissue in the wound owing to the long period during which the anterior chamber remains empty. Colombo holds the opinion that a so-called filtering cicatrix does not occur in the absence of uveal tissue. He sums up the question thus: "Such a fistula is in all probability formed by the presence of a more or less considerable involvement of uveal tissue, such involvement being also concerned with the irido-cyclitis that so commonly follows the operation. To the presence of such a fistula the late cases of deep infection are due."

Colombo says nothing about the tendency to early appearance of lens opacity in trephined eyes, but his theory has, if correct, something suggestive in this connection as well. In his view the ideal operation must get some involvement of uveal tissue which need only be minimal and invisible to ordinary clinical examination.

E. E. H.

\section{INJURIES OF THE EYE FROM HIGH VOLTAGE CURRENTS}

Morax, V. (Paris).-Lesions of iris, ciliary body, and lens consecutive to discharge of high voltage currents. Annal. d'Oculistique, Vol. CLV., July, I9I8. 